\title{
Is Diabrotica Virgifera Virgifera Still Considered a Dangerous Pest From Crops Of Romania?
}

\author{
Ioana GROZEA ${ }^{1 *}$, Raluca TRUSCA $^{1)}$, Ramona STEF ${ }^{1)}$, Levente MOLNAR ${ }^{1)}$, Mihaela FERICEAN ${ }^{1}$, Silvia \\ PRUNAR $^{11}$, Valentin MAZĂRE ${ }^{1)}$, Ionela DOBRIN ${ }^{2)}$ \\ 1)Faculty of Agriculture, Banat's University of Agricultural Sciences and Veterinary Medicine“Regele \\ Mihai I al României" from Timisoara,Calea Aradului,119,Romania. ${ }^{2)}$ Faculty of Agriculture, University of \\ Agricultural Science and Medicine Veterinary, București, B-dul Marasti, 59, Romania \\ ${ }^{*}$ Corresponding author, e-mail: ioana_entomol@yahoo.com
}

Bulletin UASVM Horticulture 71(2) / 2014

Print ISSN 1843-5254, Electronic ISSN 1843-5394

DOI:10.15835/buasvmcn-hort:10339

\begin{abstract}
Lately, Diabrotica virgifera virgifera Le Conte adults (western corn rootworm) (Coleoptera: Chrysomelidae) extended the range of host plants and also the spreading area in Romania. Though, until recently it was associated only with corn plant (it highlighted the research in Europe) today we can say that this invasive insect, in adult stage, became oligophagous. The current state of research in the field, somewhat restrained, outlines the monitoring aspects of morphology, biology, control and less at plant atractivity. This is the main reason in addressing current topics. Also, if we want to answer the question is Diabrotica virgifera virgifera still considered a dangerous pest from crops of Romania? the answer is definitely positive. The research took place over the course of tho years of study 2011 and 2012. In our studies we used observation cages type I and II (small cages and high cages). Thus for the evaluation of trophic preferences were achieved through the determination of frequency and intensity of attacks on various plants. In the experimental covered setting is obvious attraction towards other than corn comparative with uncovered setting. By far, the preferred were plants from Cucurbitaceae and Leguminosae. According to the observations made on the leaves with the highest average attack occurred at the plants of melon, soybean and beans. The damage done by insects on flowers have highlighted orientation towards plants of sunflower, cucumber and melon. Between variants down to the various plant species in relation to the total number of leaves, flowers, leaves and flowers attacked. Actually, this species invaded the corn crops in western, southern counties, the Nordic and central Romania and damaged few crops. But we supposed that in follow soon will be present throughout the country and the attractiveness of the new plants will grow.
\end{abstract}

Keywords: Diabrotica virgifera virgifera (Le Conte), host plants, adult, invasive pest.

Introduction. Diabrotica virgifera virgifera Le Conte (DvvLC), most often called western corn rootworm, is considered by most researchers specialists, as the most dangerous insect-pest in corn cultures (Krysan and Miller, 1986). Originally from America, insect (Apple et al., 1977) under study, it was gradually expanded and other continents (Kiss et al., 2005). The first damage was recorded in a corn crop of Kansas (Burkhardt and Bryson, 1955). According to a risk analysis, the corn is the main host plant for DvvLC. Adults feed on pollen, silk leaves and young corn grains (Macleod et al., 2007). There are also other plants that ensure the survival of Diabrotica pest (Moeser and Vidal, 2004, 2005; ONeal et al., 2002).
Aims and objectives. The aim of this studies is finding other host plants other than corn. The objectives are axed on identifying new host plants in terms of frequency of attack.

Materials and methods. The experimental field research studies, conducted in 2011-2012, were made in the Experimentaland Didactic Station of BUASVM Timisoara. The experimental field was divided in 7 variants (plots) with different plant species. In each pots was installed one emergence cage. Small plants established as host plants or potential host plants were surveyed inside of low individual cages (I) while for the tall plants were used high cages (II). In each cage, respectively, individual experimental variant, were introduced 
Tab. 1. Comparative data regarding the extent of damage at level of leaves and flowers; numerical quatifically of total plants, under study, in relation with percent of attacked plants

\begin{tabular}{|c|c|c|c|c|}
\hline Type of host plant & $\begin{array}{l}\text { Total number of } \\
\text { leaves / plant }\end{array}$ & $\begin{array}{l}\text { Total number } \\
\text { of flower/ } \\
\text { plant }\end{array}$ & $\begin{array}{l}\text { The average } \\
\text { freqvency of leaf } \\
\text { attack }\end{array}$ & $\begin{array}{l}\text { The average } \\
\text { freqvency of } \\
\text { flower attack }\end{array}$ \\
\hline bean & 39 & 7 & $35,31^{000}$ & $42,85^{-}$ \\
\hline cucumber & 90 & 21 & $0,16^{\mathrm{xxx}}$ & $42,85^{-}$ \\
\hline sunflower & 20 & 38 & $1,71^{\mathrm{xxx}}$ & $92,1^{000}$ \\
\hline melon & 57 & 8 & $3,4^{\mathrm{xxx}}$ & $37,5^{\mathrm{xxx}}$ \\
\hline zucchini & 32 & 2 & $0,14^{\mathrm{xxx}}$ & $50^{000}$ \\
\hline watermelon & 94 & 15 & $0,22^{\mathrm{xxx}}$ & $6,66^{\mathrm{xxx}}$ \\
\hline soybean & 93 & 30 & $22,59^{000}$ & $20^{\mathrm{xxx}}$ \\
\hline Average & 60,714 & 17,285 & 9,07 & 41,70 \\
\hline \multicolumn{3}{|c|}{$\begin{array}{l}{ }^{000} \text { _very significant negative } \\
\text { xxx_very significant positive } \\
\text { - no diferences }\end{array}$} & $\begin{array}{l}\text { LD5 } \%=1,248 \\
\text { LD1 } \%=1,730 \\
\text { LD0.1\%=2,403 }\end{array}$ & $\begin{array}{l}\text { LD5 } \%=1,486 \\
\text { LD1 } \%=2,060 \\
\text { LD0.1\%=2,862 }\end{array}$ \\
\hline
\end{tabular}

about 50 adults.The beetles were collected from corn crops located near experimental plots. When the plants were blooming, these were introduced in cages. Have been traced their behaviour and also the orientation to plants. Damaged plants were analyzed and quantified.

Results and Discussion. Comparative observation between plants showed that beetles of $D v v L C$ species have differentiated preferences. The plants under observation were: sunflower, zucchini, soybean (ONeal et al., 2002), bean, cucumber, melon and watermelon. The data in the table 1, show that not all plants under study are evident damaged, with repercussions on the development of plants. Plants not affected by insect are zucchini and watermelon; the mean values of number of leaves/flowers were situated between 0,00 and 1,00 . Plants affected by attack of adultinsects recorded values from 1 to 21 /leaves and 3-35/flowers. Of all the studied plant, a percent of $8.94 \%$ was affected to leaves and $13.65 \%$ was affected to flowers.

So, according to the observations made on the leaves with the highest average attack occurred at the plants of melon, soybean and bean. The damage on flowers have highlighted orientation towards plants of sunflower, cucumber and melon.

Conclusion. The preferred were plants from Cucurbitaceae and Leguminosae. So, if we want to answer the question is Diabrotica virgifera virgifera still considered a dangerous pest from crops of Romania? the answer is definitely positive.

\section{REFERENCES}

1. Apple JW, Chiang HC, English LM, French LJ, AJ Keaster, Krause GF, Mayo ZB, Munson JD, Musick GJ, Owens JC et al (1977). Impact of northern and western corn rootworm larvae on field corn. North Central Res: 239.

2. Burkhardt CC, Bryson HR (1955). Notes on distribution of the western corn rootworm Diabrotica virgifera lec. In Kansas (Coleoptera: Chrysomelidae). J Kansas Entomol Society 28: 1 - 3 .

3. Kiss J, Komáromi J, Bayar K, Edwards CR, Hatala-Zsellér I (2005). Western corn rootworm (Diabrotica virgifera virgifera LeConte) and the crop rotation systems in Europe, pp. 189-220. In: S. Vidal, U. Kuhlmann, C.R. Edwards (Eds.) Western corn rootworm ecology and management. CABI

4. Krysan JL, Miller TA (1986). Methods for the study of pest Diabrotica. Springer, NY.

5. Macleod A, Baker RHA, Cheek S, Eyre D, Cannon RJ (2007). Pest risk analysis for Diabrotica virgifera virgifera, Central Science Laboratory, Sand Hutton, York yo41 1lz (UK).

6. Moeser J, Vidal S (2004). Do Alternative Host Plants Enhance the Invasion of the Maize Pest Diabrotica virgifera virgifera (Coleoptera: Chrysomelidae, Galerucinae) in Europe? Environ Entomol 33(5):1169-1177.

7. Moeser J, Vidal S (2005). Nutritional resources used by the invasive maize pest Diabrotica virgifera virgifera in its new South-East-European distribution range. Ento Exp Appl 114(1):55-63.

8. ONeal ME, DiFonzo CD, Landis DA (2002). Western Corn Rootworm (Coleoptera: Chrysomelidae). Feeding on Corn And Soybean Leaves Affected by Corn Phenology. Environ Entomol 31: 285-292. 